\title{
Free-standing hybrid films based on graphene and porous carbon particles for flexible supercapacitors
}

\author{
Guillermo A. Ferrero, Marta Sevilla, and Antonio B. Fuertes ${ }^{*}$ \\ Instituto Nacional del Carbón (CSIC), P.O. Box 73, Oviedo 33080, Spain \\ *Corresponding author: abefu@incar.csic.es
}

\section{Abstract}

Free-standing flexible solid-state supercapacitors are attracting attention as power supply for electronic equipment. Here we report a novel strategy to fabricate free-standing flexible hybrid papers made up of porous carbon particles combined with graphene sheets. The synergetic effect between the carbon particles and the graphene sheets entails two important advantages: a) binder-free electrodes formed by carbon particles can be built up with the assistance of the graphene sheets and b) the restacking of the graphene sheets is avoided to a great extent due to the fact that the carbon particles act as spacers. These hybrid papers combine important properties for their use in solid-state supercapacitors: a) large specific surface area, b) good electrical conductivity, c) high packing density and d) excellent flexibility. They exhibit a volumetric electrochemical performance which is clearly superior to electrodes fabricated with carbon particles agglomerated with a binder. In addition, they achieve an excellent areal capacitance $\left(103 \mathrm{mF} \mathrm{cm}^{-2}\right)$ at current densities as high as $1400 \mathrm{~mA} \mathrm{~cm}{ }^{-2}$ and are able to deliver a large amount of energy $(\sim 12$ $\mu \mathrm{Wh} \mathrm{cm}^{-2}$ ) at high power densities $\left(316 \mathrm{~mW} \mathrm{~cm}^{-2}\right)$. In this work, a robust, flexible and high-performance solid-state supercapacitor has been assembled using such hybrid papers. 
Keywords: graphene paper, flexible, free-standing, supercapacitors, carbon nanoparticles. 


\section{Introduction}

Activated carbon is an essential ingredient of most electrodes used in electric double-layer capacitors (EDLC). This is because of their low cost, high surface area, controllable pore size, excellent chemical stability and good electronic conductivity. ${ }^{1-3}$ ENREF 6 However, the fabrication of carbon-based electrodes involves a shaping process that commonly entails the addition of foreign inactive substances (i.e. a binder and a conductive additive), which substantially reduces the capacitance of the EDLC system on both a volumetric and gravimetric basis. ${ }^{4,5}$ Moreover, the carbon electrodes fabricated in this way are unbendable and, in consequence, they are unsuitable for in flexible energy storage systems.

Flexible energy storage devices have recently attracted increasing attention for incorporation in foldable electronic equipment (i.e. displays, mobile phones, computers, etc.). ${ }^{6-9}$ Because of its unique properties, graphene has emerged as an important building block for the fabrication of electrodes in energy storage systems, such as supercapacitors and Li-ion batteries. ${ }^{5,10}$ The singular structure of graphene sheets makes them suitable for assembling freestanding, thin films that combine an excellent flexibility with a good electrical conductivity. ${ }^{11}$ For these reasons, graphene has become an essential component in the fabrication of electrodes for flexible energy storage systems. ${ }^{5}$ In order to successfully exploit the excellent properties of graphene for electrochemical applications, the re-stacking of the graphene sheets needs to be minimized. ${ }^{12,13}$ By taking advantage of the ability of graphene sheets to form free-standing films, and by inserting several types of electroactive substances within the graphene framework it is possible to fabricate electrodes with 
enhanced properties. Indeed, the synthesis of hybrid films made up of graphene sheets and conductive polymers or inorganic oxides has been investigated in some depth. As examples, several authors have explored the insertion of polyaniline or polypyrrole into graphene films. ${ }^{14-18}$ In this respect, Xu et al. synthesized by vacuum filtration paper-like composites films made up of reduced graphene oxide ( $\mathrm{rGO}$ ) and polyaniline, which contain $44 \mathrm{wt} \%$ rGO and exhibit a high capacitance $\left(214 \mathrm{~F} \mathrm{~g}^{-1}\right)$ and a high cycling stability. ${ }^{17}$ Davies et al. used a pulsed electrodeposition technique to create flexible, and uniform graphene/polypyrrole hybrid films that exhibit a high energy density of around $33 \mathrm{Wh} \mathrm{kg}^{-1} .^{18}$ Moreover, the incorporation of certain inorganic substances, such as nanoparticles of manganese oxides, ${ }^{19-21}$ iron oxide, ${ }^{22}$ tin oxide ${ }^{23}$ or Ni-based oxides/hydroxides ${ }^{24-27}$ confined within the graphene films has likewise attracted widespread attention. Thus, Gao et al. reported the design of solid-state asymmetric supercapacitors based on free-standing carbon nanotube/graphene and $\mathrm{Mn}_{3} \mathrm{O}_{4}$ nanoparticles/graphene films. ${ }^{19}$ Similarly, Chen et al. used N-doped graphene films to support nickel nanoparticles which were used as catalysts for the oxygen evolution reaction (OER). ${ }^{27}$

Unlike the abundant literature centered around graphene/(polymeric or inorganic substances) composite films, there are no reports on the fabrication of self-standing, binder-free and flexible hybrid films formed by graphene and porous carbon particles. Worth noting in this context is the use of non-porous carbon black nanoparticles ${ }^{28,29}$ and carbon nanotubes ${ }^{30,31}$ that are used as spacers to avoid the self-restacking of graphene sheets.

In this work, we present a novel synthesis strategy for fabricating flexible, self-standing and binder-free hybrid films made up of highly porous carbon 
particles combined with graphene sheets. Graphene acts as a scaffold that retains and interconnects the carbon particles. However, it is important to mention that when these composites are used as electrodes for energy storage systems (i.e. supercapacitors and batteries), graphene should not be considered just as a simple host material to encapsulate and interconnect the carbon particles, but also acts as an electroactive substance. In addition, the porous carbon particles not only provide a large surface area, but also act as spacers that reduce the stacking of graphene sheets. These hybrid films provide three important advantages compared to the conventional electrodes produced by agglomeration of porous carbon particles. Firstly, because the hybrid films are bendable, porous carbon particles can be used in flexible energy storage systems. Secondly, the fabrication process is notably simplified because the hybrid films are obtained by means of a simple vacuum filtration of a dispersion of carbon particles and graphene sheets. Thirdly, the electrochemical properties (i.e. specific capacitance or stored energy density) are clearly superior because no foreign substance is required. To demonstrate our synthesis strategy, we selected two types of micrometer-size porous carbon particles: a) microporous carbon nanosheets produced by the carbonization of potassium citrate ${ }^{32}$ and b) N-doped micro-mesoporous carbon microspheres synthesized by chemical activation with potassium bicarbonate in the presence of melamine of hydrochar microspheres obtained by the hydrothermal

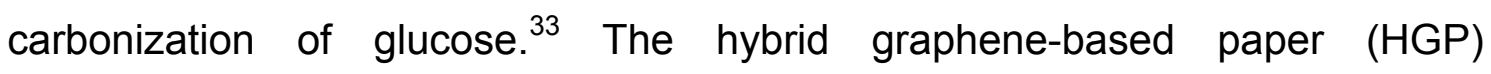
synthesized with these carbon particles are free-standing, flexible, and show a high performance as electrodes in supercapacitors (SC). Thus, the HGP reported herein exhibit a better performance, on a volumetric basis, than the 
electrodes fabricated by the agglomeration of the carbon particles with a binder. In addition, these hybrid papers combine a high areal energy density with a large areal power density. Even more importantly, the supercapacitors fabricated with the HGP electrodes exhibit high areal capacitances of $160 \mathrm{mF}$ $\mathrm{cm}^{-2}$ in $\mathrm{H}_{2} \mathrm{SO}_{4}$. Moreover, they can also operate at high current densities of $1442 \mathrm{~mA} \mathrm{~cm}^{-2}$ and exhibit an excellent rate performance (65\% retention), delivering a large amount of energy of $\sim 7.1 \mu \mathrm{Wh} \mathrm{cm}^{-2}$ at an ultra-high power density of $\sim 579 \mathrm{~mW} \mathrm{~cm}^{-2}$. Furthermore, in this study the HGP composite has been successfully integrated in a flexible solid supercapacitor.

\section{Results and Discussion}

\section{Synthesis and characterization of the hybrid graphene papers (HGPs)}

We recently reported a simple way of fabricating free-standing and flexible graphene papers (GP). ${ }^{34}$ In that study, we proved that the supercapacitors built up with this type of electrodes exhibit an excellent stability and high areal power (up to $280 \mathrm{~mW} \mathrm{~cm}{ }^{-2}$ ) and energy (up to $60 \mu \mathrm{Wh} \mathrm{cm} \mathrm{cm}^{-2}$ ). In the present work we have taken a step forward and investigated the fabrication of hybrid papers made up of graphene units and highly porous carbon particles. The synthesis procedure of these hybrid systems is illustrated in Scheme 1. Once the graphene aerogel has been oxidized with hydrogen peroxide $\left(\mathrm{H}_{2} \mathrm{O}_{2}\right)$, the resulting suspension of holey graphene units is mixed with the porous carbon particles and, then, vacuum filtered. The as-obtained film is dried and peeled off from the membrane and a free-standing flexible paper is obtained. In these experiments, two types of porous carbon particles with a well-defined morphology were used: microporous carbon nanosheets (CK) and micromesoporous carbon microspheres (CS). The amount of carbon particles 
incorporated into the hybrid paper is optimized to $60 \%$. The synthesis procedure of these carbon particles is given as Supporting Information.

The graphene units obtained after oxidation with $\mathrm{H}_{2} \mathrm{O}_{2}$ consist of two types of nanostructures (i.e. wrinkled sheets and nanoscrolls, see Figure S1a and S1b) which contain numerous basal nanoholes (size $\sim 2-4 \mathrm{~nm}$ ) caused by the etching action of hydrogen peroxide (see Figures S1c). These basal pores are important as they enhance the transport of ions throughout the entire film. ${ }^{35}$ A typical graphene paper obtained from these graphene units has a layered structure (see Figure S1d), with a thickness of $30 \mu \mathrm{m}$, a volumetric density of $0.8 \mathrm{~g} \mathrm{~cm}^{-3}$ and a specific surface area (measured by methylene blue) of $700 \mathrm{~m}^{2}$ $g^{-1} \cdot 34$

The carbon nanosheets (CK) used in the experiments were obtained by direct carbonization of potassium citrate as reported by Sevilla and Fuertes, ${ }^{32}$ whereas the carbon microspheres (CS) were synthesized by the chemical activation of glucose hydrochar with a mixture of potassium bicarbonate and melamine. ${ }^{33}$ SEM and TEM inspections of the morphology of these particles reveals that the carbon nanosheets consist of thin layers that are fully interconnected and the carbon microspheres consist of spherical particles with a diameter of $250 \pm 40 \mathrm{~nm}$ (see Figure S2). Both types of carbon particles are highly porous and have a high specific surface area $\left(2230 \mathrm{~m}^{2} \mathrm{~g}^{-1}\right.$ for CK and $3230 \mathrm{~m}^{2} \mathrm{~g}^{-1}$ for CS), a large pore volume and a porosity which is made up almost exclusively of micropores in the case of CK and of micro-mesopores in the CS sample (see Table 1 and Figure S3).

The HGPs obtained by vacuum filtration of a dispersion of graphene units and carbon particles, were then subjected to a pressure of up to $500 \mathrm{MPa}$. As 
illustrated in Figure 1a, the HGPs are free-standing and flexible and they have a thickness of $\sim 35 \mu \mathrm{m}$ for GP-CK and GP-CS, as can be appreciated by the cross sections in Figure 1b. The SEM and TEM images of the HGP papers containing carbon nanosheets and carbon microspheres reveal that these particles are mixed together with the graphene units (see Figures 1c-f).

The chemical and structural properties of the HGP samples were investigated by elemental analysis, X-ray diffraction (XRD), Raman spectroscopy and X-ray photoelectron spectroscopy (XPS). The chemical composition of the different samples is given in Table 2. As a consequence of the treatment with hydrogen peroxide, the graphene paper exhibits a relatively high content in oxygen groups $(25.85 \% \mathrm{wt},(\mathrm{C} / \mathrm{O})$ ratio $\sim 3.7)$. The incorporation of the carbon particles with low oxygen contents (8.5 \% wt for CK and $6.4 \% \mathrm{wt}$ for CS) led to a decrease in the overall oxygen content of the HGP samples and the values of the $(\mathrm{C} / \mathrm{O})$ ratios are $\sim 5.1$ for GP-CK and $(\mathrm{C} / \mathrm{O}) \sim 6$ for GP-CS. In addition, some nitrogen is also present in the films, originating either from the graphene sheets (as a consequence of the ammonia/hydrazine ${ }^{36}$ used in the reduction process) or from the $\mathrm{N}$-doped microspheres (see Figure $\mathrm{S} 4$ for the high-resolution XPS N1s spectrum of the GP-CS paper). The presence of oxygen and nitrogen functional groups is an important feature due to their capacitance enhancement through reversible redox reactions and also due to their ability to improve the wettability of the electrodes. ${ }^{37,38}$ The nature and distribution of the oxygen functional groups present in the GP and HGP samples was investigated by XPS (Figure 2a). The deconvoluted C1s spectrum corresponding to the graphene papers shows the presence of $\mathrm{C}=\mathrm{O}, \mathrm{C}=\mathrm{N}$ and/or amide groups (288.6 eV), C-O groups (286.8 eV) and O-C=O groups (290.4 
$\mathrm{eV})$, besides the $\pi-\pi^{*}$ shake-up satellite (292.2 eV), C sp ${ }^{2}(284.5 \mathrm{eV})$ and $\mathrm{C} \mathrm{sp}{ }^{3}$ and C-N (285.6 eV) (see Table S1). ${ }^{39-43}$ The XRD patterns in Figure $2 \mathrm{~b}$ reveal a broad band at around $24.7^{\circ}$. In the case of the GP sample, this result indicates a certain stacking of few graphene layers. A large increase in the low-angle scattering is observed in the XRD patterns of the GP-CK and GP-CS samples, which reveals an abundance of micro- and mesopores. ${ }^{44}$ Raman spectroscopy further confirms the amorphous nature of the graphene papers. As can be seen in Figure 2c, all the graphene papers exhibit a strong $D\left(1340 \mathrm{~cm}^{-1}\right)$ and $G$ $\left(1590 \mathrm{~cm}^{-1}\right.$ ) bands, a negligible 2D band at $2649 \mathrm{~cm}^{-1}$ and $D+G$ band at 2930 $\mathrm{cm}^{-1}$. Slight differences between the $I_{D} / I_{G}$ ratio values of GP and GP-CK/GP-CS are observed, which indicates that the incorporation of carbon particles does not increase the degree of disorder. The high electrical conductivity of the carbon particles gives rise to a notable increase in the electrical conductivity in the synthesized HGPs, as reflected in Table 2. Thus, the HGP films exhibit electrical conductivities that are 14 (GP-CK) and 2 (GP-CS) times greater than those of the GP film. The surface area of the materials was deduced from the amount of methylene blue adsorbed by the sample in an aqueous solution. This made it possible to compare the surface areas of the hybrid samples HGP with that of the graphene paper GP. The results shown in Figure $2 d$ reveal that the incorporation of carbon particles led to a remarkable increase of the surface area, to $1010 \mathrm{~m}^{2} \mathrm{~g}^{-1}$ for the GP-CK and to $1040 \mathrm{~m}^{2} \mathrm{~g}^{-1}$ in case of the GP-CS.

Comparison between the electrodes made up of carbon particles and binder and the binder-free graphene-(carbon particles) papers

The electrochemical performance of the electrodes formed by carbon particles agglutinated with the aid of a binder and that of the hybrid graphene 
papers was investigated in a two-electrode cell using $1 \mathrm{M} \mathrm{H}_{2} \mathrm{SO}_{4}$ as electrolyte. The physical characteristics of the electrodes once compacted by applying a pressure of up to $500 \mathrm{MPa}$ are summarized in Table 3. It can be seen that the hybrid papers have high packing density values of $0.66 \mathrm{~g} \mathrm{~cm}^{-3}$, which are double those obtained with the electrodes formed exclusively by carbon particles $\left(0.3-0.35 \mathrm{~g} \mathrm{~cm}^{-3}\right)$, although slightly lower than that of the graphene paper $\left(0.8 \mathrm{~g} \mathrm{~cm}^{-3}\right)$. These results anticipate a good electrochemical performance on a volumetric basis for both the binder-free GP and HGP samples. Indeed, whereas on a gravimetric basis, the electrodes formed exclusively by carbon particles exhibit a higher specific capacitance, as can be deduced from the cyclic voltammograms (Figures S5a and S5b) and chargedischarge experiments at different current densities (Figures S5c and S5d), when the results are shown on a volumetric basis, the binder-free HGP electrodes exhibit a superior performance. Thus, as can be seen in Figures 3ab, the volumetric capacitance of the flexible papers is considerably higher than that of the carbon particles over the whole current density range. In addition, the capacitance retention for the graphene paper with carbon nanosheets is higher than that of just the carbon particles (Figure 3c). In the case of the micromesoporous carbon microspheres, both electrodes exhibit a similar capacitance fading, although the hybrid carbon paper can withstand higher current densities than the CS sample, like GP-CK. All of this translates into enhanced volumetric energy and power characteristics for the HGPs, as can be observed in the Ragone-like plot in Figure $3 \mathrm{~d}$. To be more precise, the use of HGPs leads to a $50 \%$ increase in volumetric energy density and they can operate at higher power densities. 


\section{Electrochemical performance of GP and HGP samples}

The cyclic voltammograms (CVs) of the supercapacitors assembled with the HGP samples are represented in Figures $4 a-4 b$ for different scan rates. The CVs clearly show that the HGPs exhibit capacitive behavior of up to $5 \mathrm{~V} \mathrm{~s}^{-1}$, suggesting ultra-fast ion transport. This high-rate capability is also corroborated by the variation of the normalized capacitance with frequency (Figure S6a), with relaxation time constants in the $0.17-0.22 \mathrm{~s}$ range. In addition, the Nyquist plots in Figure S6b exhibit short Warburg regions, indicating smooth ion diffusion. Interestingly, a decrease in equivalent series resistance (ESR) is observed when the carbon particles are introduced. Specifically, GP-CS and GP-CK exhibit values of $0.21 \Omega$ and $0.15 \Omega$ respectively, in comparison to $0.32 \Omega$ for GP, which is in agreement with their higher electronic conductivity (see Table 1). A comparison of the $\mathrm{CV}$ curves at $5 \mathrm{mV} \mathrm{s}^{-1}$ in Figure $4 \mathrm{c}$ reveals a clear enhancement of capacitance for the HGPs compared to the graphene paper (GP). The material which leads to the highest cell areal capacitance is the hybrid graphene paper assembled with the microspheres. This can be ascribed to its higher specific surface area.

Galvanostatic charge-discharge (CD) experiments were performed at current densities in the $0.24-1442 \mathrm{~mA} \mathrm{~cm}^{-2}$ range. At a low current density of 0.5 $\mathrm{mA} \mathrm{cm} \mathrm{cm}^{-2}$ the CD plots (see Figure S6c) are perfectly symmetrical for all the materials (with coulombic efficiencies > $96 \%$ ). The stability of the supercapacitors was assessed by performing CD at $12 \mathrm{~mA} \mathrm{~cm} \mathrm{~cm}^{-2}$ over 5000 cycles. As can be observed in Figure S6d, the capacitance retention for the hybrid graphene papers is $>96 \%$. When the current density is increased up to $\sim 230 \mathrm{~mA} \mathrm{~cm}{ }^{-2}$, a small IR drop is observed (see Figure 4d), confirming the 
results previously obtained by EIS and CV, and demonstrating their excellent rate capability. The variation of the cell areal capacitance with current density is illustrated in Figure 4e. It can be seen that the GP-CS paper exhibits the highest cell areal capacitance, $160 \mathrm{mF} \mathrm{cm}^{-2}$ (at low discharge rates), which implies an enhancement of $55 \%$ in capacitance compared to GP $\left(\sim 100 \mathrm{mF} \mathrm{cm}{ }^{-2}\right)$. On the other hand, when carbon nanosheets (CK) are used, the cell areal capacitance is slightly lower $\left(136 \mathrm{mF} \mathrm{cm} \mathrm{cm}^{-2}\right)$, but still higher than GP. These differences correlate well with the differences in the specific surface area and porosity (see previous section and Table 1). When the current density is increased up to ultra-high values (> $1150 \mathrm{~mA} \mathrm{~cm}{ }^{-2}$ ), a capacitance retention of $\sim 65 \%$ is still obtained in the case of the HGPs. In fact, GP-CS can operate at current densities as high as $1442 \mathrm{~mA} \mathrm{~cm}^{-2}$ and still deliver $\sim 103 \mathrm{mF} \mathrm{cm}^{-2}$. It is clear that the hybrid graphene papers developed in this work compare favorably with the best graphene materials ${ }^{45-53}$ and hybrid graphene materials ${ }^{15,28,54-56}$ reported in the literature (see Table S2). The combination of a unique graphene structure made up of holey graphene wrinkled sheets and graphene nanoscrolls with porous carbon particles of small size, ensures fast ion transport rates. In addition, the carbon particles serve as effective separators, preventing the agglomeration of the graphene sheets. The excellent areal energy and power characteristics of the assembled supercapacitors are evident in the Ragone-like plot in Figure $4 \mathrm{f}$. Indeed, the GP-CS supercapacitor is able to store $\sim 27 \mu \mathrm{Wh}$ $\mathrm{cm}^{-2}$ at an areal power density of $0.12 \mathrm{~mW} \mathrm{~cm}^{-2}$, which represents an increase of $55 \%$ with respect to GP and a higher value also than that of GP-CK ( $23 \mu \mathrm{Wh}$ $\mathrm{cm}^{-2}$ ). More importantly, the HGPs can work up to $316 \mathrm{~mW} \mathrm{~cm}^{-2}$ delivering an areal energy density as high as $11.5 \mu \mathrm{Wh} \mathrm{cm}^{-2}$. In summary, the hybrid 
graphene papers can store more energy and deliver it more quickly than any graphene paper/film developed so far. ${ }^{45-51,53}$

\section{Electrochemical performance of solid-state supercapacitors with HGP papers}

In order to study the graphene papers in greater depth, a solid-state supercapacitor was assembled by using $\mathrm{H}_{2} \mathrm{SO}_{4}$-PVA as the gel electrolyte. For this purpose, GP-CS was selected due to the excellent results obtained in the previous section. Before assembling the supercapacitor, the electrodes were pressed to form a thin film of $55 \mu \mathrm{m}$. Figure $\mathrm{S7a}$ shows an image of the asprepared supercapacitor which is made up of two rectangular pieces of graphene paper $13 \mathrm{~mm} \times 26 \mathrm{~mm}$. The excellent electrochemical performance of GP-CS in $\mathrm{H}_{2} \mathrm{SO}_{4}$ is here confirmed when $\mathrm{H}_{2} \mathrm{SO}_{4}$-PVA is used as the electrolyte. Thus, comparison of the CVs at $20 \mathrm{mV} \mathrm{s}^{-1}$ of the solid-state SCs assembled with GP and GP-CS electrodes reveals that the HGP exhibits a superior cell areal capacitance (see Figure 5a). Likewise, the solid-state (GP-CS)-based SC is able to operate up to $52 \mathrm{~mA} \mathrm{~cm}{ }^{-2}$ with a capacitance retention of $\sim 58 \%$, as evidenced in Figure 5b. Especially remarkable is the cell capacitance value at low discharge rates, i.e. $165 \mathrm{mF} \mathrm{cm}^{-2}$, which is superior to the value obtained with the GP-solid state SC $\left(108 \mathrm{mF} \mathrm{cm}^{-2}\right)$ and among the best of those reported in the literature for graphene films ${ }^{48,49}$ and hybrid graphene films in $\mathrm{H}_{2} \mathrm{SO}_{4}-\mathrm{PVA}$ electrolyte, ${ }^{45,53,57,58}$ and also for other flexible supercapacitors ${ }^{59-62}$ (see Table S3). Moreover, the volumetric capacitance of the solid device is calculated to be $18 \mathrm{~F} \mathrm{~cm}^{-3}$ at low discharge rates, which is higher than that of a graphene hydrogel film $\left(8 \mathrm{~F} \mathrm{~cm}^{-3}\right.$ at $1 \mathrm{~A} \mathrm{~g}^{-1}$, and $6 \mathrm{~F} \mathrm{~cm}^{-3}$ at $\left.20 \mathrm{~A} \mathrm{~g}^{-1}\right)$, flexible graphene $\left(0.42 \mathrm{~F} \mathrm{~cm}^{-3} \text { at } 1 \mathrm{~A} \mathrm{~g}^{-1}\right)^{63}$ and a functionalized graphene hydrogel $\left(1.4 \mathrm{~F} \mathrm{~cm}^{-3}\right.$ at 
$\left.1 \mathrm{~A} \mathrm{~g}^{-1}\right) \cdot{ }^{53}$ Finally, the electrochemical performance of the solid-state device was visually confirmed by powering a red light-emitting diode (LED) with a minimum operating turn-on potential of $1.7 \mathrm{~V}$ using just two supercapacitors connected in series (Figure S7b).

The flexible solid-state SC also exhibits an excellent mechanical robustness in the bending test. Thus, the cyclic voltammograms obtained at various bending angles show nearly the same capacitive behavior (see Figure $5 c$ ), which demonstrates that the change in the electrochemical properties is negligible under different bending angles. In order to test the durability of the solid-state device, galvanostatic charge-discharge was performed at a current density of $13 \mathrm{~mA} \mathrm{~cm}{ }^{-2}$ under a bending angle of $180^{\circ}$ over 5000 cycles. As can be seen in Figure $5 d$, the flexible device retains $91 \%$ of its capacitance and the calculated coulombic efficiency is always above $96 \%$.

\section{Conclusions}

In summary, we have presented a procedure for fabricating free-standing flexible hybrid papers made up of porous carbon particles combined with wrinkled graphene sheets and graphene nanoscrolls. Such hybrid papers combine several important properties for their use as electrodes in solid-state supercapacitors: a) a high specific surface area, b) a good electrical conductivity, c) a high packing density and d) an excellent flexibility. The hybrid graphene papers exhibit a volumetric electrochemical performance which is clearly superior to that of the electrodes made with carbon particles agglomerated with a binder and, in consequence, they are able to deliver $50 \%$ more energy density than these carbon particles and furthermore, they can 
work at higher power densities. These hybrid graphene papers can also provide an excellent cell areal capacitance $\left(103 \mathrm{mF} \mathrm{cm}^{-2}\right)$ at current densities as high as $1442 \mathrm{~mA} \mathrm{~cm}^{-2}$, an outstanding rate performance (65\% capacitance retention), and a long cycle life (> $96 \%$ retention after 5000 cycles). In addition, they show high areal energy and power densities, being able to deliver a large amount of energy $\left(\sim 12 \mu \mathrm{Wh} \mathrm{cm}{ }^{-2}\right)$ at high power densities $\left(316 \mathrm{~mW} \mathrm{~cm}^{-2}\right)$. A robust and flexible solid-state supercapacitor assembled using the hybrid paper GP-CS showed an enhanced capacitive performance, with an areal capacitance of 108 $\mathrm{mF} \mathrm{cm}{ }^{-2}$ at $52 \mathrm{~mA} \mathrm{~cm}^{-2}$, which represents a capacitance retention of $58 \%$ for a 100 -fold increase in current density. 


\section{Experimental}

\section{Fabrication of the graphene papers}

Graphene oxide (GO) was prepared by using a modified Hummer's method as reported elsewhere ${ }^{64}$. The GO solid was dispersed in water by ultrasonication (Sonics, Ultrasonic Vivracell, $500 \mathrm{~W}, 40 \%$ ) for $1.5 \mathrm{~h}$ to make a $\mathrm{GO}$ aqueous dispersion with a concentration that was adjusted to $0.5 \mathrm{mg} \mathrm{GO} \mathrm{mL} \mathrm{mL}^{-1}$. To prepare an aqueous graphene colloidal suspension, $120 \mathrm{~mL}$ of $\mathrm{GO}$ dispersion (0.5 mg mL $\mathrm{m}^{-1}$ ) was mixed with $0.24 \mathrm{~mL}$ hydrazine (35 wt \% in water, Aldrich) and $0.42 \mathrm{~mL}$ ammonia (30 wt \%, Aldrich) in a Teflon vessel, stirred for $15 \mathrm{~min}$ and then treated at $100^{\circ} \mathrm{C}$ for $3 \mathrm{~h}$ [22]. The Teflon vessel containing the as-formed graphene dispersion was immersed in a nitrogen liquid in order to obtain high freezing rates. The frozen dispersion was placed in a lyophilizer (Telstar Cryodos) and freeze-dried at a temperature of $-51^{\circ} \mathrm{C}$ and at a pressure of 0.06 mbar. The resulting graphene aerogel was dispersed in an aqueous solution of $\mathrm{H}_{2} \mathrm{O}_{2}$ (concentration: 0 - 5 wt \%) and treated, under stirring, at $100{ }^{\circ} \mathrm{C}$ (reflux) for $4 \mathrm{~h}$. The graphene paper (here denoted as GP) was made by vacuum filtering the oxidized graphene dispersion through a regenerated cellulose membrane $(0.45 \mu \mathrm{m}$, Sartorius $)$ and then drying it at $50^{\circ} \mathrm{C}$. Subsequently, the film was subjected to a pressure of up to $500 \mathrm{MPa}$.

In the case of the hybrid graphene papers, two kinds of carbon particles were used to obtain the final graphene hybrid papers, i.e. carbon nanosheets and carbon microspheres, whose detailed synthesis procedure is explained in the experimental section of the Supporting Information. For the synthesis of the 
hybrid papers, the carbon particles were dispersed in water followed by ultrasonication. The graphene aerogel dispersed in an aqueous solution of $\mathrm{H}_{2} \mathrm{O}_{2}$ was mixed with the carbon particle solution. The dispersion was then vacuum filtered through a regenerated cellulose membrane. Finally, the graphene hybrid paper was dried at $50{ }^{\circ} \mathrm{C}$ and peeled from the membrane. The resulting graphene papers were denoted as GP-CK when the carbon particles used were carbon nanosheets and GP-CS when they were carbon microspheres. The final mass ratio of carbon particles in the total mass of graphene paper was $60 \%$ for both hybrid graphene papers.

\section{Material Characterization}

Scanning electron microscopy (SEM) images were obtained on a Quanta FEG650 (FEI) instrument, whereas transmission electron microscopy (TEM) images were recorded on a JEOL (JEM 2100-F) apparatus operating at $200 \mathrm{kV}$. The specific surface area of the hybrid graphene papers synthesized at low temperature was determined by the methylene blue adsorption method as

described by McAllister et al. ${ }^{65}$ X-ray diffraction (XRD) patterns were obtained on a Siemens D5000 instrument operating at $40 \mathrm{kV}$ and $20 \mathrm{~mA}$, using $\mathrm{Cu} \mathrm{KR}$ radiation. The Raman spectra were recorded on a Horiva (LabRam HR-800) spectrometer. The source of radiation was a laser operating at a wavelength of $514 \mathrm{~nm}$ and at a power of $25 \mathrm{~mW}$. X-ray photoelectron spectroscopy (XPS) was carried out on a Specs spectrometer, using Mg KR (1253.6 eV) radiation from a double anode at $150 \mathrm{~W}$. The dc electrical conductivity of the graphene papers was determined on a homemade apparatus by pressing the papers between two plungers into a hollow Nylon cylinder (inner diameter of $8 \mathrm{~mm}$ ), and 
applying a pressure of 7.1 MPa. Elemental analysis $(\mathrm{C}, \mathrm{H}, \mathrm{N}$ and $\mathrm{O})$ of the samples was carried out on a LECO CHN-932 microanalyzer.

\section{Characterization of the electrochemical supercapacitors}

The electrochemical measurements were performed in two-electrode Swagelok ${ }^{\mathrm{TM}}$ type cells using $1 \mathrm{M} \mathrm{H}_{2} \mathrm{SO}_{4}$ as the electrolyte. The electrochemical capacitors were assembled using two graphene paper/carbon electrodes of comparable mass and thickness, electrically isolated by a glassy fibrous separator. In the case of the graphene hybrid papers, the electrodes were cut directly from the prepared papers. Meanwhile, in the case of the carbon particles, the electrodes were prepared by mixing $85 \mathrm{wt} \%$ of active material, 10 wt \% of polytetrafluoroethylene (PTFE) binder (Aldrich, 60 wt \% suspension in water) and 5 wt \% of the conductive additive Super C65 (Timcal company). Electrochemical characterization was performed using a computer-controlled potentiostat (Biologic VMP3 multichannel generator) and it consisted of cyclic voltammetry experiments, electrochemical impedance spectroscopy studies (EIS) and galvanostatic charge/discharge cycling tests (CD).

Electrochemical impedance spectroscopy (EIS) measurements were performed at open circuit voltage (i.e. $0 \mathrm{~V}$ ) in the discharged stated within the frequency range of $1 \mathrm{mHz}$ to $100 \mathrm{kHz}$ and a $10 \mathrm{mV} \mathrm{AC}$ amplitude. Bode plots of the dependence of the capacitance on frequency and Nyquist plots were recorded to characterize the impedance of the tested samples. The specific gravimetric capacitance of the supercapacitor, $C_{E I S}\left(F g^{-1}\right)$, was calculated according to the following formula and normalized with respect to the highest specific gravimetric capacitance, i.e. capacitance at $1 \mathrm{mHz}$ : 


$$
C_{E S S}=\frac{2 \mid \operatorname{m}(\mathbb{Z})}{\pi \mid \operatorname{Im}(Z))^{2}+(R e(Z))^{2} \mid \cdot m}
$$

where $f$ is the operating frequency $(\mathrm{Hz})$, and $\operatorname{Im}(Z)$ and $\operatorname{Re}(Z)$ are the imaginary and real components of the total device resistance $(\mathrm{Ohm})$. The relaxation time constant, $\tau_{0}$, which separates the capacitive and the resistive behavior of the supercapacitor, was deduced from the frequency $f_{0}$ as follows: $\tau_{0}=1 / f_{0}$, where $f_{0}$ is obtained from the real capacitance plot at $\mathrm{C}^{\prime}=\mathrm{C}_{1 \mathrm{mHz}} / 2$. The equivalent series resistance (ESR) was calculated from the intercept of the high frequency semicircle loop with the real impedance axis at the highest frequency. ${ }^{66,67}$

Cyclic voltammetry experiments (CVs) were performed between 0 and $1.1 \mathrm{~V}$ at increasing sweep rates from $1 \mathrm{mV} \mathrm{s}^{-1}$ to $5 \mathrm{~V} \mathrm{~s}^{-1}$. Plots of cell areal capacitance vs. voltage were calculated using the formula:

$$
C_{\text {owll }}=\frac{l}{v+5}
$$

where I = current, $v=$ scan rate and $\mathrm{S}=$ geometrical area of the device.

The electrode specific capacitance was calculated on the basis of the total mass of the electrode, which in the case of the carbon particles includes the carbon black added and the binder. Plots of differential capacitance vs. voltage were traced using the formula:

$$
C-\frac{4 \cdot I}{v \cdot m}
$$

where $\mathrm{I}=$ current $(\mathrm{A}), \mathrm{v}=$ scan rate $\left(\mathrm{V} \mathrm{s}^{-1}\right)$ and $\mathrm{m}=$ total mass (grams) of both electrodes in the supercapacitor.

Galvanostatic charge/discharge cycling was performed in the same voltage range at increasing current densities from 0.2 to $1442 \mathrm{~mA} \mathrm{~cm}{ }^{-2}$. The cell 
areal capacitance determined from the galvanostatic cycles was calculated by means of the formula:

$$
C_{\text {sed }}=\frac{l}{\left(d V_{d}\right) \cdot S}
$$

where $\mathrm{dV} / \mathrm{dt}=$ the slope of the discharge curve.

The specific gravimetric capacitance of a single electrode ( $F g^{-1}$ ) determined from the galvanostatic cycles was calculated by means of the formula:

$$
C=\frac{4 l}{\left(d V_{\text {elt }}\right) \cdot m}
$$

Taking into account the dependence of specific capacitance on the voltage in the present materials due to the presence of pseudocapacitance, the selection of an appropriate voltage range for the determination of the slope is very important to avoid overestimating the specific capacitance. As most supercapacitors are operated in the range of $V_{\max }$ to approximately $1 / 2 V_{\max }$, the upper half of the discharge curve was used to determine the slope of the discharge curve. ${ }^{68}$

To trace the Ragone-like plots, the areal energy $\left(\mu \mathrm{Wh} \mathrm{cm}^{-2}\right)$ and the areal power $\left(\mathrm{mW} \mathrm{cm}^{-2}\right)$ densities were calculated using the following formulae:

$$
\begin{aligned}
& \mathrm{E}=\frac{1}{2} \mathrm{C}_{\text {cell }} \Delta \mathrm{V}_{\mathrm{d}}^{2} \\
& \mathrm{P}=\frac{\mathrm{E}}{\Delta \mathrm{t}_{\mathrm{d}}}
\end{aligned}
$$

where $\Delta V_{d}$ is the operation voltage $\left(V_{\max }-I R_{d r o p}\right)$ and $\Delta_{t d}$ is the discharge time. 


\section{Fabrication of all-solid-state supercapacitors}

The PVA/ $\mathrm{H}_{2} \mathrm{SO}_{4}$ gel electrolyte was prepared as follows: $2 \mathrm{~g}$ of PVA (MW: 9000, Aldrich) was dispersed in $20 \mathrm{~mL} \mathrm{H}_{2} \mathrm{SO}_{4} 1 \mathrm{M}$ and, then the mixture was heated at $50{ }^{\circ} \mathrm{C}$ under continuous stirring until the solution became transparent (around $30 \mathrm{~min}$ ). After that, the graphene paper electrodes (size: $13 \mathrm{~mm} \times 26$ mm) were immersed in $\mathrm{H}_{2} \mathrm{SO}_{4} 1 \mathrm{M}$ and dried at room temperature. In order to assemble the solid-state device, the $\mathrm{H}_{2} \mathrm{SO}_{4}$-PVA was poured on a glassy fibrous separator. The two electrodes were then attached to the separator on one side and to a graphite film collector on the other. Finally, the symmetric supercapacitor was fabricated by sandwiching all the components between two flexible PET films and pressing them so that the polymer gel in the separator would infiltrate into the GP and GP-CS.

\section{Acknowledgments}

This research work was supported by the FICYT Regional Project (GRUPIN14102), and the Spanish MINECO-FEDER (CTQ2015-63552-R). G. A. F. thanks the MINECO for his predoctoral contract. 


\section{List of Tables and Figures}

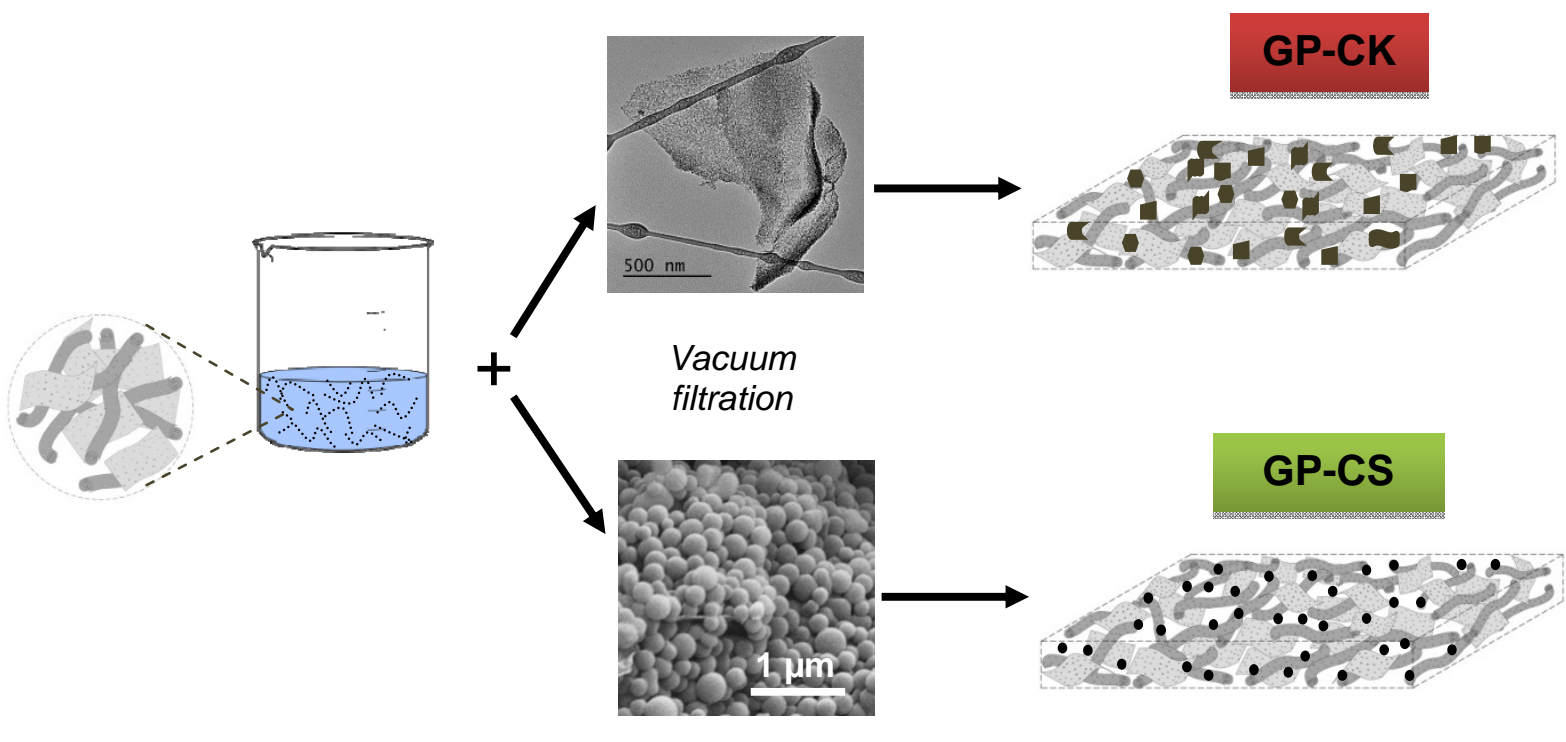

Scheme 1. Illustration of the synthesis procedure.

Table 1. Textural properties of the porous carbon particles

\begin{tabular}{ccccc}
\hline Sample Code & $\mathrm{S}_{\mathrm{BET}}\left(\mathbf{m}^{2} \mathbf{g}^{-1}\right)$ & $\mathrm{V}_{\mathbf{p}}\left(\mathbf{c m}^{3} \mathbf{g}^{-1}\right)^{\mathrm{a}}$ & $\mathrm{V}_{\mathrm{mi}}\left(\mathbf{c m}^{3} \mathbf{g}^{-1}\right)^{\mathbf{b}}$ & $\mathrm{V}_{\text {meso }}\left(\mathbf{c m}^{3} \mathbf{g}^{-1}\right)^{\mathbf{c}}$ \\
\hline CK & 2230 & 1.11 & 0.84 & 0.27 \\
CS & 3230 & 2.2 & 1.01 & 1.19 \\
\hline
\end{tabular}

${ }^{a}$ Pore volume determined at $\mathrm{P} / \mathrm{P}_{0}=0.95$. ${ }^{\mathrm{b}}$ The micropore volume was obtained by applying the Dubinin-Radushkevich (D-R) method to $\mathrm{N}_{2}$ adsorption branch. ${ }^{c}$ The mesopore volume obtained from the difference between the pore volume $\left(\mathrm{V}_{\mathrm{p}}\right)$ and micropore volume $\left(\mathrm{V}_{\mathrm{mi}}\right)$.

Table 2. Chemical composition and electrical conductivity of the samples.

\begin{tabular}{lcccccc} 
& \multicolumn{4}{c}{ Elemental analysis (wt \%) } & (C/O) & $\begin{array}{c}\text { Comic } \\
\text { Atomple }\end{array}$ \\
\cline { 2 - 5 } & $\mathbf{C}$ & $\mathbf{H}$ & $\mathbf{O}$ & $\mathbf{N}$ & $\begin{array}{c}\text { ratio } \\
\left(\mathbf{S ~ m}^{-1}\right)\end{array}$ \\
\hline GP & 71.3 & 0.99 & 25.85 & 1.86 & 3.7 & 5.2 \\
CK & 91.52 & 0.22 & 8.48 & nil & 14.4 & 371.3 \\
CS & 88.5 & 0.69 & 6.37 & 4.47 & 18.5 & 103.8 \\
GP-CK & 77.88 & 0.65 & 20.21 & 1.26 & 5.1 & 75 \\
GP-CS & 78.2 & 0.89 & 17.36 & 3.55 & 6.0 & 10.4 \\
\hline
\end{tabular}


Table 3. Properties of the electrodes after subjecting them to a pressure of up to $500 \mathrm{MPa}$.

\begin{tabular}{ccccc}
\hline Type of electrode & $\begin{array}{c}\text { Sample } \\
\text { Code }\end{array}$ & $\begin{array}{c}\text { Packing density } \\
\left(\mathbf{g ~ \mathbf { ~ m } ^ { - 3 }}\right)\end{array}$ & $\begin{array}{c}\text { Thickness } \\
(\boldsymbol{\mu \mathbf { m }})\end{array}$ & $\begin{array}{c}\text { Areal Density } \\
\left(\mathbf{m g ~ c m}^{-\mathbf{2}} \mathbf{)}\right.\end{array}$ \\
\hline Paper (Binder-free) & GP & 0.8 & 30 & 2.38 \\
Particles with binder & CK & 0.35 & 75 & 2.50 \\
Particles with binder & CS & 0.32 & 75 & 2.35 \\
Hybrid paper (Binder-free) & GP-CK & 0.66 & 35 & 2.31 \\
Hybrid paper (Binder-free) & GP-CS & 0.66 & 35 & 2.30 \\
\hline
\end{tabular}



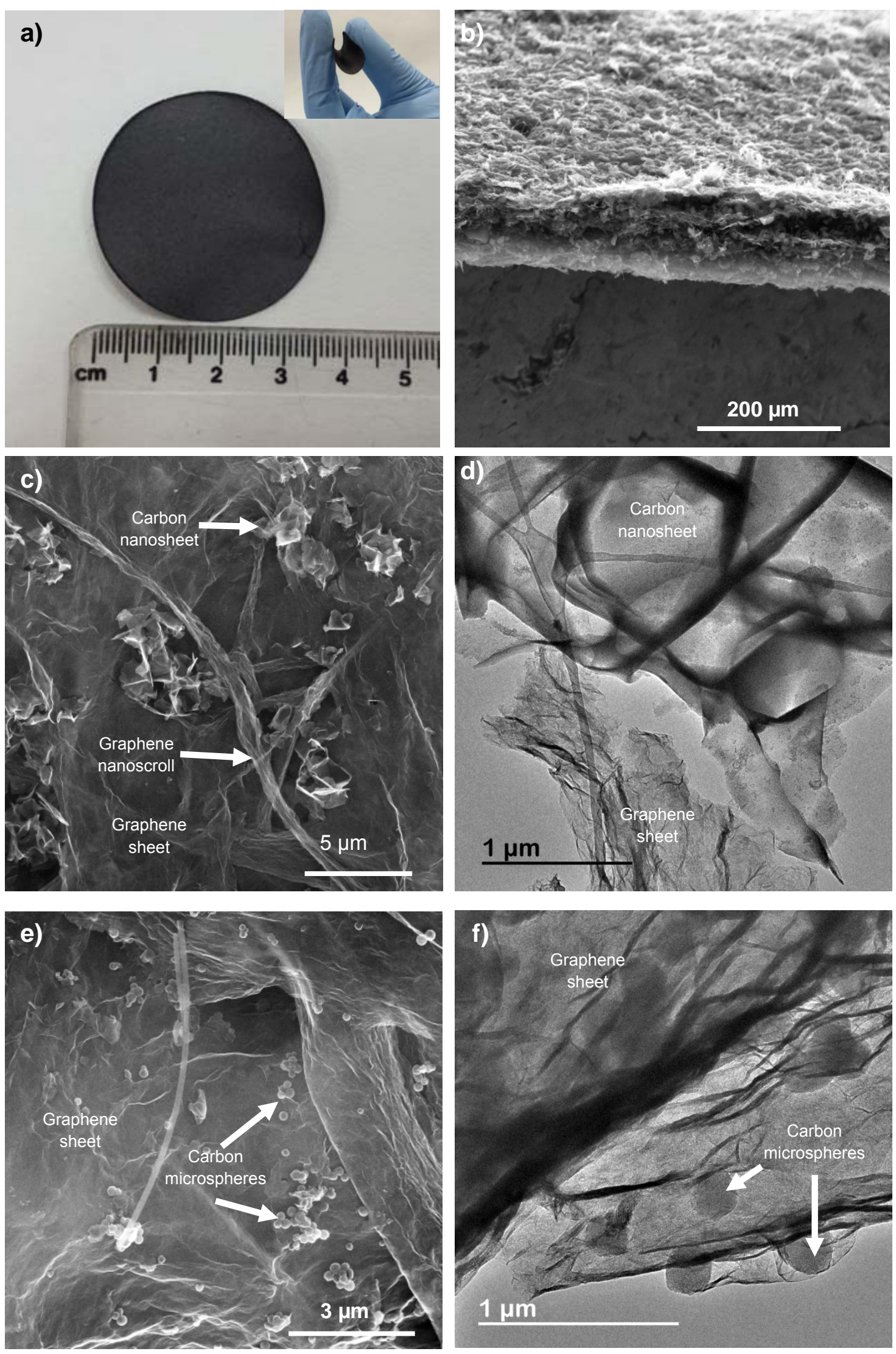
Figure 1. (a) Digital images of the HGP paper (GP-CK), (b) cross-section of a HGP (GP-CS), (c) SEM and (d) TEM images of the GP-CK film, and (e) SEM and (f) TEM images of the GP-CS film.

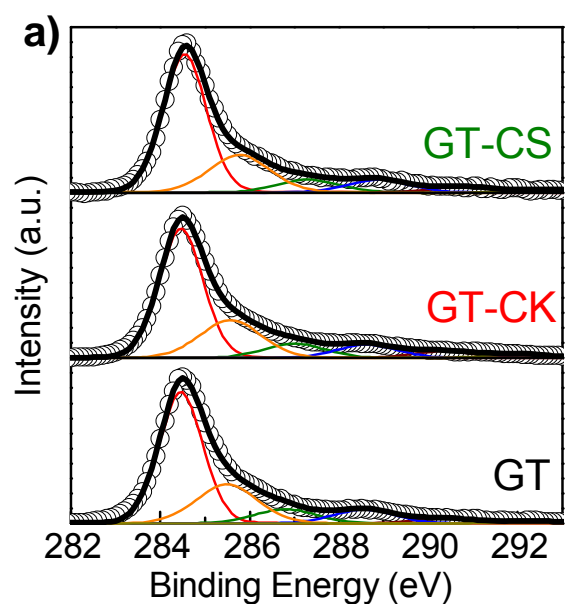

b)
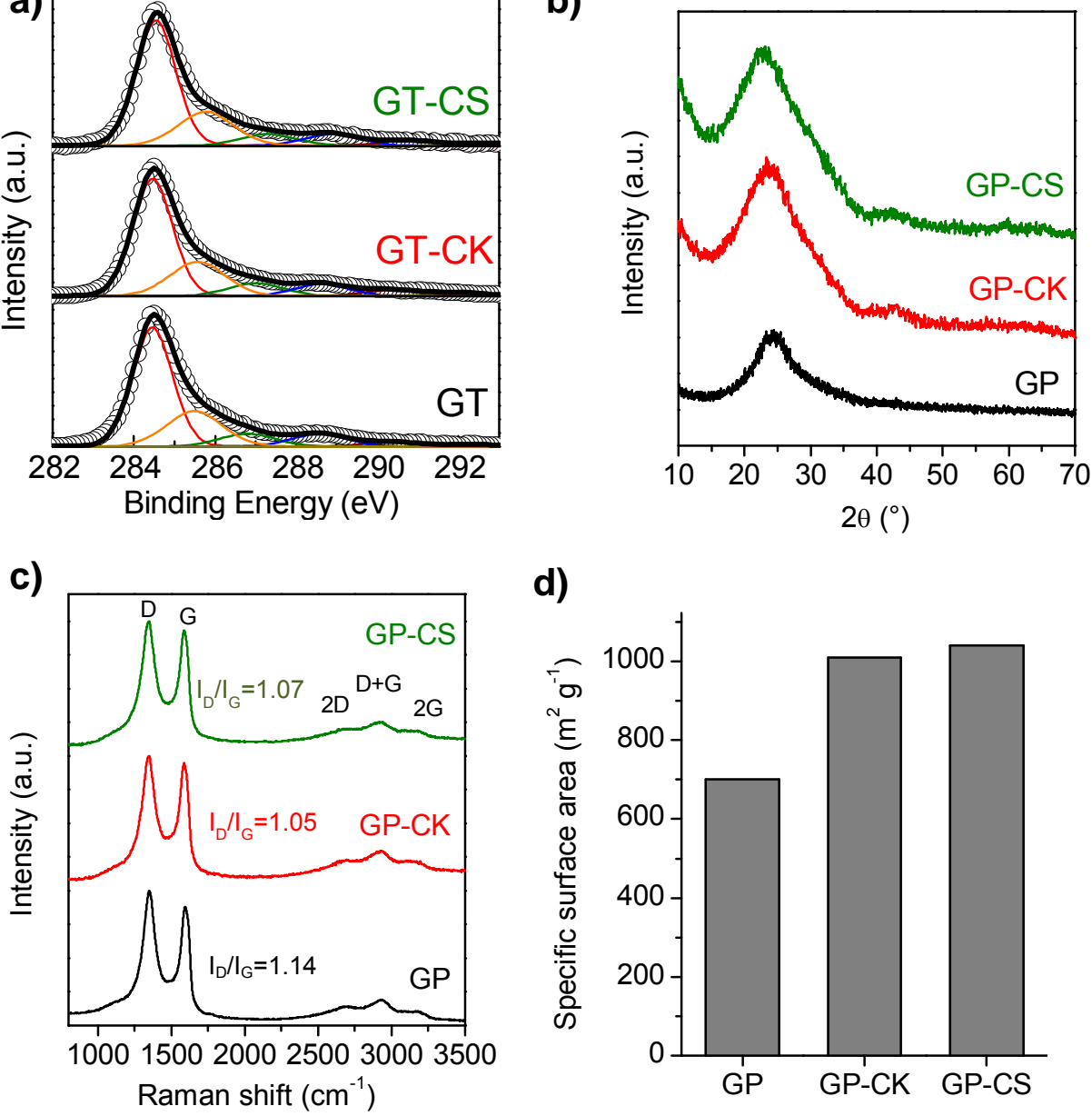

d)

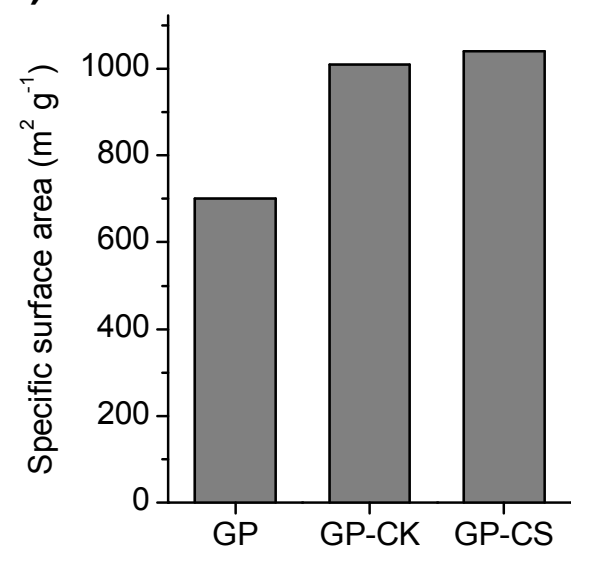

Figure 2. (a) High-resolution XPS C1s spectra, (b) XRD patterns, (c) Raman spectra, and (d) specific surface area of the GP, GP-CK and GP-CS papers. 
a)

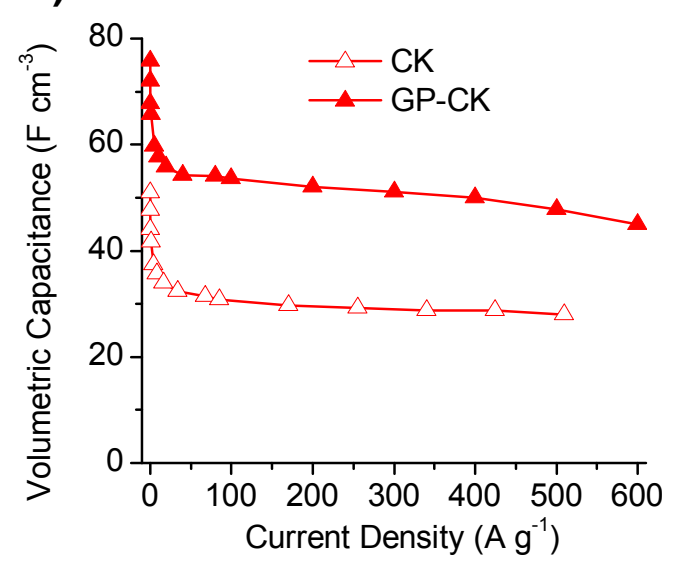

c)

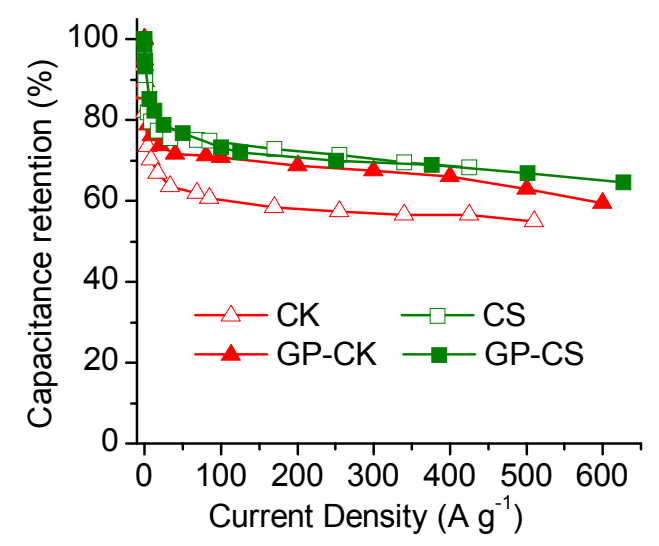

b)

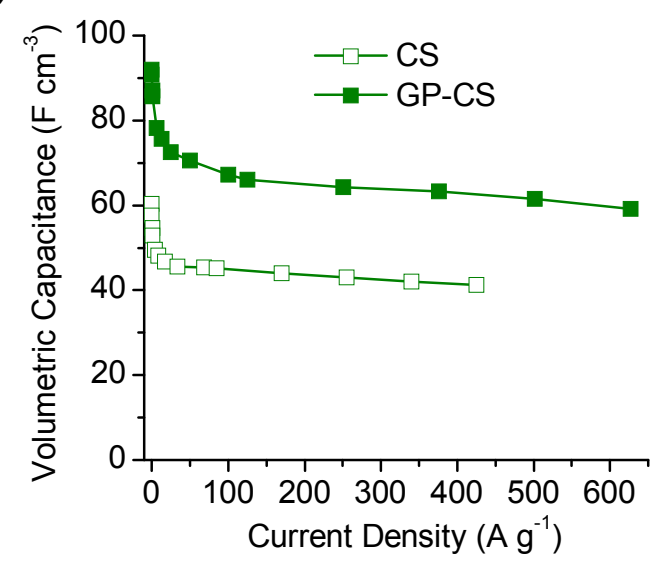

d)

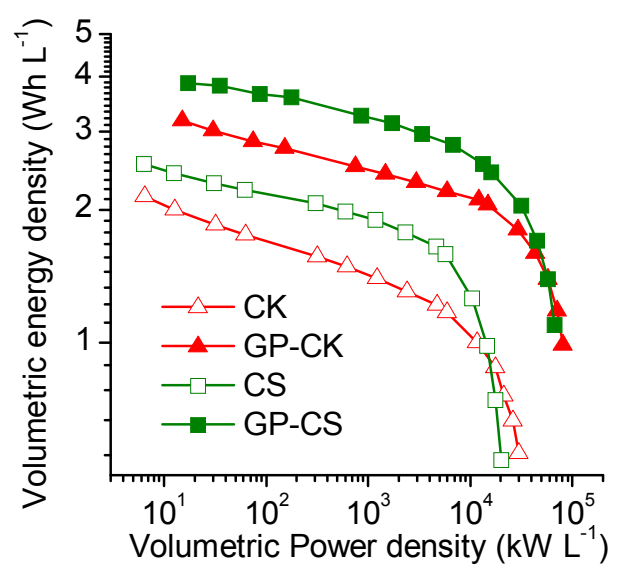

Figure 3. Variation of the electrode volumetric capacitance with the current density for (a) the CK and GP-CK samples and (b) the CS and GP-CS samples, (c) capacitance retention and (d) Ragone-like plot in volumetric units for the CK ,GP-CK, CS and GP-CS samples. Electrolyte: $1 \mathrm{M} \mathrm{H}_{2} \mathrm{SO}_{4}$. 

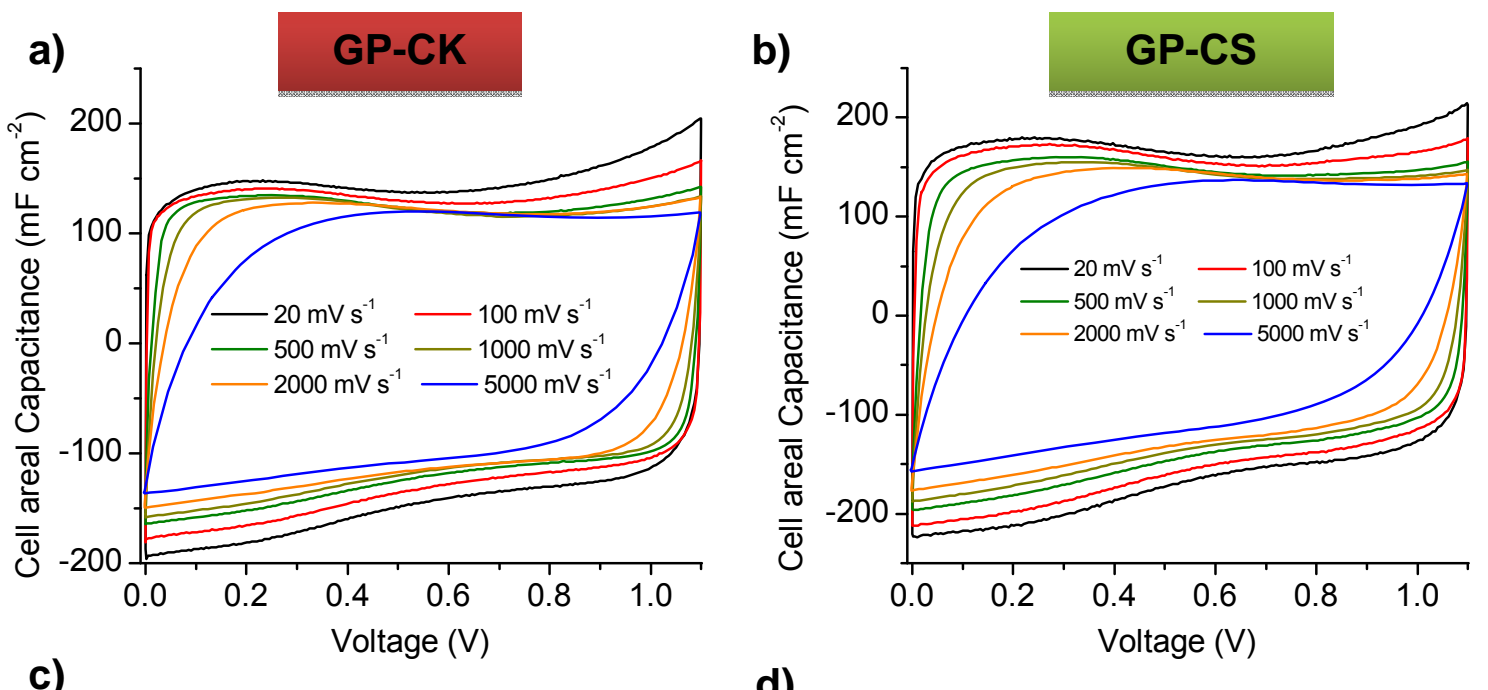

d)
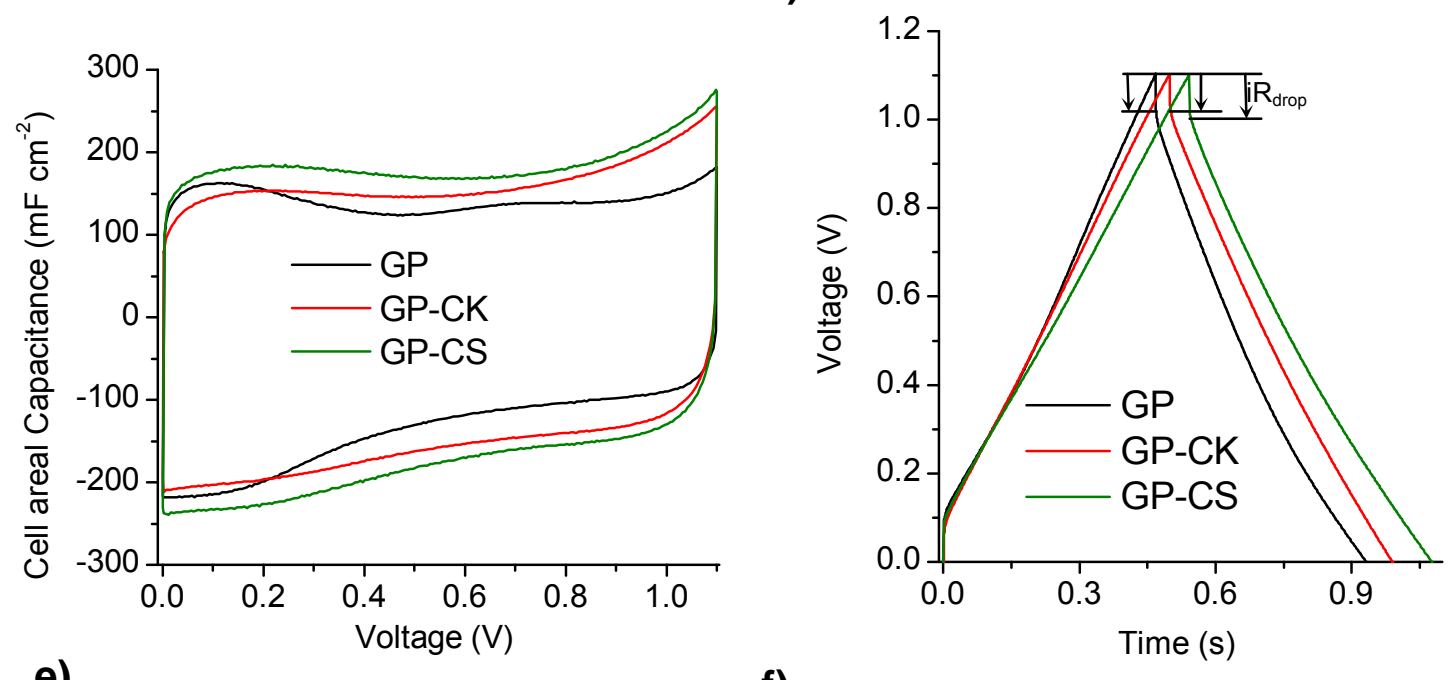

f)
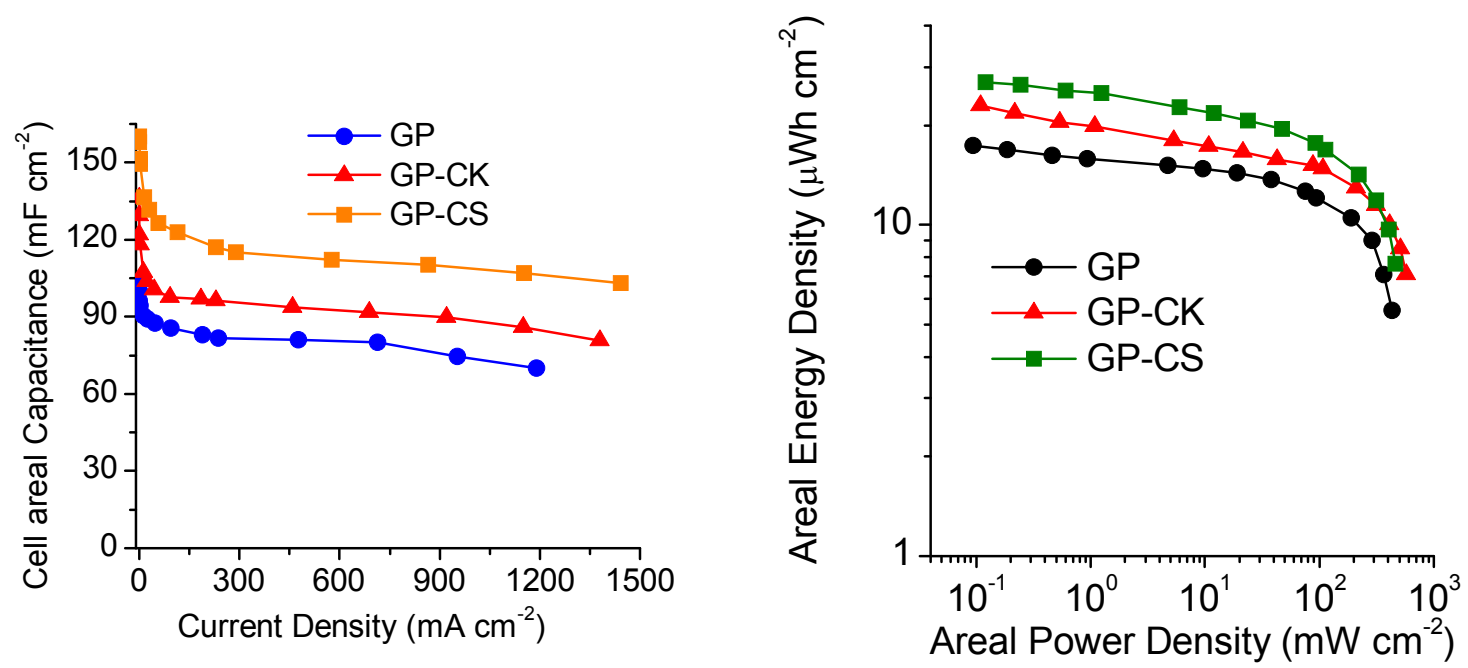

Figure 4. Cyclic voltammograms at different scan rates for the (a) GP-CK and (b) GP-CS papers, (c) cyclic voltammograms at $5 \mathrm{mV} \mathrm{s}^{-1}$ for the different graphene papers, (d) galvanostatic charge-discharge cycles at $\sim 230 \mathrm{~mA} \mathrm{~cm}^{-2}$, 
(e) variation of the areal capacitance with the current density and (f) Ragonelike plot for the GP, GP-CK and GP-CS papers. Electrolyte: $1 \mathrm{M} \mathrm{H}_{2} \mathrm{SO}_{4}$.

a)

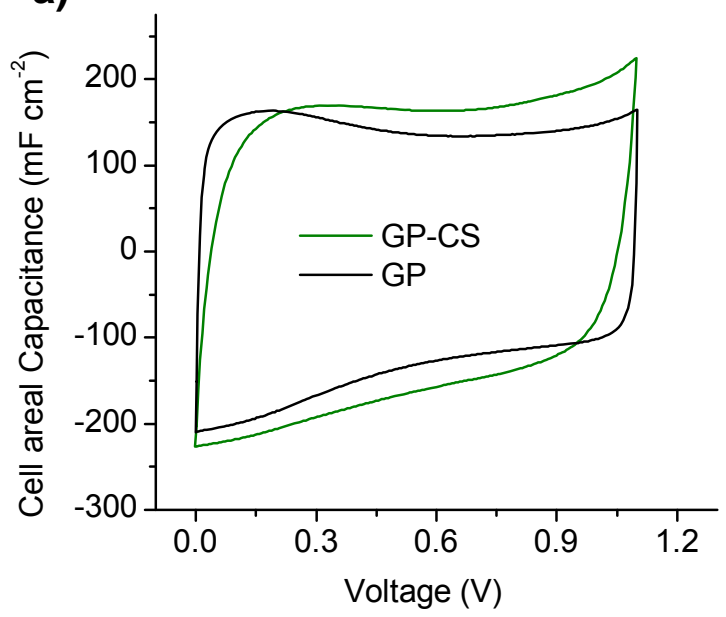

c)

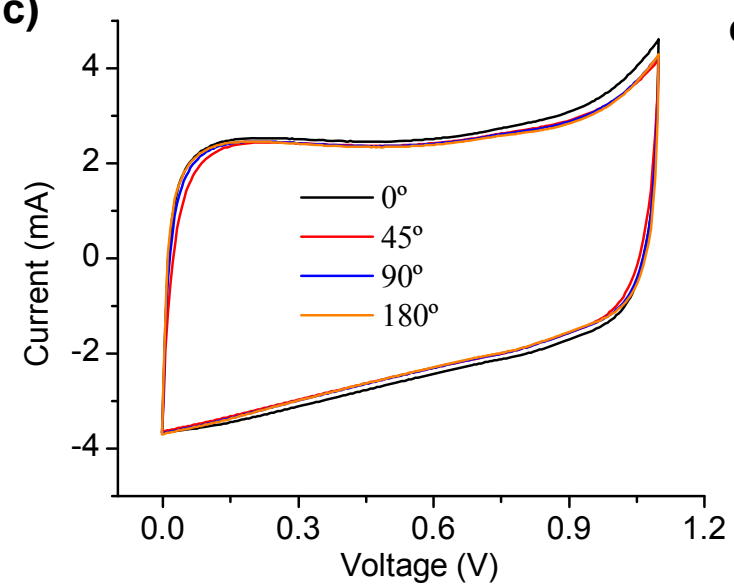

b)

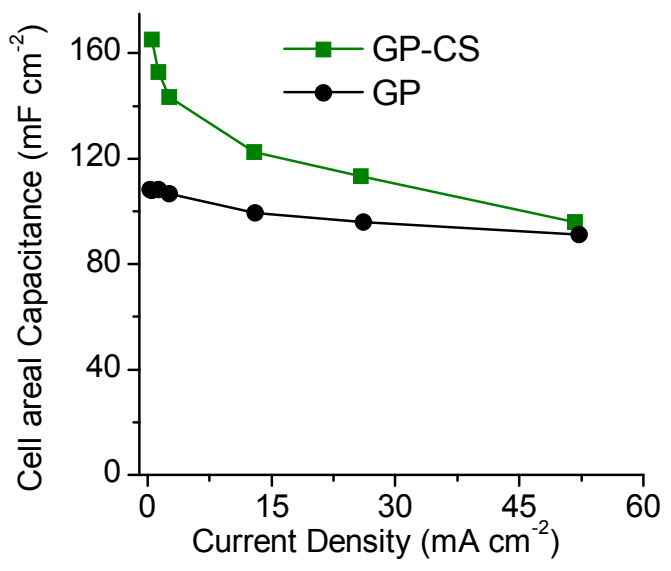

d)

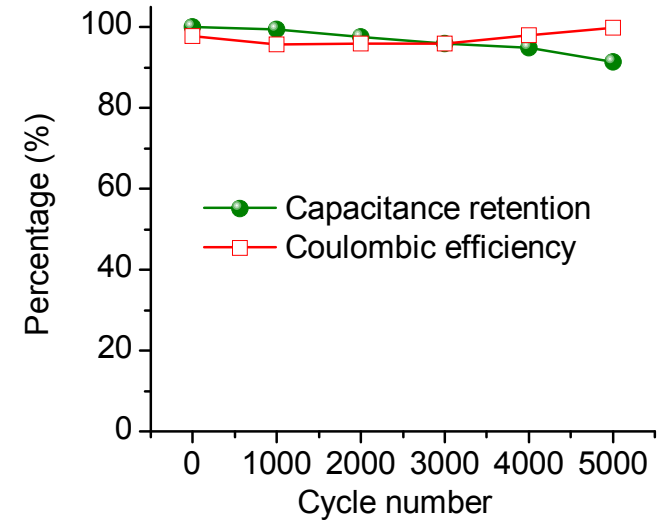

Figure 5. Solid-state supercapacitor performance (electrolyte: $\mathrm{H}_{2} \mathrm{SO}_{4}-\mathrm{PVA}$ ): (a) cyclic voltammograms at $20 \mathrm{mV} \mathrm{s}^{-1}$ and (b) rate dependence of GP- and GPCS-based supercapacitors, (c) cyclic voltammograms at $5 \mathrm{mV} \mathrm{s}^{-1}$ at different bending angles from $0^{\circ}$ to $180^{\circ}$ and (d) coulombic efficiency and long-term stability evaluated by charge-discharge cycling at a constant current of $13 \mathrm{~mA}$ $\mathrm{cm}^{-2}$ for the GP-CS supercapacitor at a bending state of $180^{\circ}$. 


\section{References}

1. M. Sevilla and R. Mokaya, Energy Environ. Sci., 2014, 7, 1250-1280.

2. A. Ghosh and Y. H. Lee, ChemSusChem, 2012, 5, 480-499.

3. E. Frackowiak, Phys. Chem. Chem. Phys., 2007, 9, 1774-1785.

4. A. B. Fuertes, G. A. Ferrero and M. Sevilla, Energy Storage Materials, 2016, 4, 154-155.

5. Y. Shao, M. F. El-Kady, L. J. Wang, Q. Zhang, Y. Li, H. Wang, M. F. Mousavi and R. B. Kaner, Chem. Soc. Rev., 2015, 44, 3639-3665.

6. X. Lu, M. Yu, G. Wang, Y. Tong and Y. Li, Energy Environ. Sci., 2014, 7, 2160-2181.

7. Y.-Z. Zhang, Y. Wang, T. Cheng, W.-Y. Lai, H. Pang and W. Huang, Chem. Soc. Rev., 2015, 44, 5181-5199.

8. X. Peng, L. Peng, C. Wu and Y. Xie, Chem. Soc. Rev., 2014, 43, 3303-3323.

9. D. Ghosh and S. O. Kim, Electronic Materials Letters, 2015, 11, 719-734.

10. W. Lv, Z. Li, Y. Deng, Q.-H. Yang and F. Kang, Energy Storage Materials, 2016, 2, 107-138.

11. W. K. Chee, H. N. Lim, Z. Zainal, N. M. Huang, I. Harrison and Y. Andou, J. Phys. Chem. C., 2016, 120, 4153-4172.

12. J. Ji, Y. Li, W. Peng, G. Zhang, F. Zhang and X. Fan, Adv. Mater., 2015, 27, 5264-5279.

13. N. Mahmood, C. Zhang, H. Yin and Y. Hou, J. Mater. Chem. A, 2014, 2, 15-32.

14. H. Choi, K.-J. Ahn, Y. Lee, S. Noh and H. Yoon, Advanced Materials Interfaces, 2015, 2, 1500117-1500117.

15. F. Xiao, S. Yang, Z. Zhang, H. Liu, J. Xiao, L. Wan, J. Luo, S. Wang and Y. Liu, Sci. Rep., 2015, 5, 9359.

16. Y. Xie, Y. Liu, Y. Zhao, Y. H. Tsang, S. P. Lau, H. Huang and Y. Chai, J. Mater. Chem. A, 2014, 2, 9142-9149.

17. Q. Wu, Y. Xu, Z. Yao, A. Liu and G. Shi, ACS Nano, 2010, 4, 1963-1970.

18. A. Davies, P. Audette, B. Farrow, F. Hassan, Z. Chen, J.-Y. Choi and A. Yu, J. Phys. Chem. C., 2011, 115, 17612-17620.

19. H. Gao, F. Xiao, C. B. Ching and H. Duan, ACS Applied Materials \& Interfaces, 2012, 4, 7020-7026.

20. A. Sumboja, C. Y. Foo, X. Wang and P. S. Lee, Adv. Mater., 2013, 25, 28092815.

21. Y. Hu, C. Guan, G. Feng, Q. Ke, X. Huang and J. Wang, Adv. Funct. Mater., 2015, 25, 7291-7299.

22. M. Li, F. Pan, E. S. G. Choo, Y. Lv, Y. Chen and J. Xue, ACS Applied Materials \& Interfaces, 2016, 8, 6972-6981.

23. J. Liang, Y. Zhao, L. Guo and L. Li, ACS Applied Materials \& Interfaces, 2012, 4, 5742-5748.

24. J. Xie, X. Sun, N. Zhang, K. Xu, M. Zhou and Y. Xie, Nano Energy, 2013, 2, $65-74$

25. S. Chen, J. Zhu, L. Qiu, D. Li and X. Wang, Chemistry - A European Journal, 2013, 19, 7631-7636.

26. M. Li, Z. Tang, M. Leng and J. Xue, Adv. Funct. Mater., 2014, 24, 7495-7502.

27. S. Chen, J. Duan, J. Ran, M. Jaroniec and S. Z. Qiao, Energy Environ. Sci., 2013, 6, 3693-3699. 
28. G. Wang, X. Sun, F. Lu, H. Sun, M. Yu, W. Jiang, C. Liu and J. Lian, Small, 2012, 8, 452-459.

29. M. Wang, J. Oh, T. Ghosh, S. Hong, G. Nam, T. Hwang and J.-D. Nam, RSC Adv., 2014, 4, 3284-3292.

30. Q. Cheng, J. Tang, J. Ma, H. Zhang, N. Shinya and L.-C. Qin, Phys. Chem. Chem. Phys., 2011, 13, 17615-17624.

31. Y. Wang, Y. Wu, Y. Huang, F. Zhang, X. Yang, Y. Ma and Y. Chen, J. Phys. Chem. C., 2011, 115, 23192-23197.

32. M. Sevilla and A. B. Fuertes, ACS Nano, 2014, 8, 5069-5078.

33. M. Sevilla and A. B. Fuertes, ChemSusChem, 2016, 9, 1880-1888.

34. G. A. Ferrero, M. Sevilla and A. B. Fuertes, ChemNanoMat, 2016, DOI: 10.1002/cnma.201600228, DOI: 10.1002/cnma.201600228.

35. Y. Xu, Z. Lin, X. Zhong, X. Huang, N. O. Weiss, Y. Huang and X. Duan, Nat Commun, 2014, 5.

36. S. Park, Y. Hu, J. O. Hwang, E.-S. Lee, L. B. Casabianca, W. Cai, J. R. Potts, H.-W. Ha, S. Chen, J. Oh, S. O. Kim, Y.-H. Kim, Y. Ishii and R. S. Ruoff, Nature Communications, 2012, 3, 638.

37. L.-Z. Fan, S. Qiao, W. Song, M. Wu, X. He and X. Qu, Electrochim. Acta, 2013, 105, 299-304.

38. L.-Z. Fan, J.-L. Liu, R. Ud-Din, X. Yan and X. Qu, Carbon, 2012, 50, 37243730 .

39. H. Darmstadt, C. Roy and S. Kaliaguine, Carbon, 1994, 32, 1399-1406.

40. S. Biniak, G. Szymański, J. Siedlewski and A. Świtkowski, Carbon, 1997, 35, 1799-1810.

41. W. Si, J. Zhou, S. Zhang, S. Li, W. Xing and S. Zhuo, Electrochim. Acta, 2013, 107, 397-405.

42. J. Xiao, X. Bian, L. Liao, S. Zhang, C. Ji and B. Liu, ACS Applied Materials \& Interfaces, 2014, 6, 17654-17660.

43. Y. Chen, R. Ma, Z. Zhou, G. Liu, Y. Zhou, Q. Liu, S. Kaskel and J. Wang, Advanced Materials Interfaces, 2015, 2, 1500199-n/a.

44. Y. Zhu, S. Murali, M. D. Stoller, K. J. Ganesh, W. Cai, P. J. Ferreira, A. Pirkle, R. M. Wallace, K. A. Cychosz, M. Thommes, D. Su, E. A. Stach and R. S. Ruoff, Science, 2011, 332, 1537-1541.

45. Z. Weng, Y. Su, D.-W. Wang, F. Li, J. Du and H.-M. Cheng, Adv. Energy Mater., 2011, 1, 917-922.

46. U. N. Maiti, J. Lim, K. E. Lee, W. J. Lee and S. O. Kim, Adv. Mater., 2014, 26, 615-619.

47. X. Yang, J. Zhu, L. Qiu and D. Li, Adv. Mater., 2011, 23, 2833-2838.

48. Y. Xu, C.-Y. Chen, Z. Zhao, Z. Lin, C. Lee, X. Xu, C. Wang, Y. Huang, M. I. Shakir and X. Duan, Nano Letters, 2015, 15, 4605-4610.

49. Y. Xu, Z. Lin, X. Huang, Y. Liu, Y. Huang and X. Duan, ACS Nano, 2013, 7, 4042-4049.

50. Z. Xiong, C. Liao, W. Han and X. Wang, Adv. Mater., 2015, 27, 4469-4475.

51. X. Yang, C. Cheng, Y. Wang, L. Qiu and D. Li, Science, 2013, 341, 534-537.

52. J. Zang, C. Cao, Y. Feng, J. Liu and X. Zhao, Sci. Rep., 2014, 4, 6492.

53. Y. Xu, Z. Lin, X. Huang, Y. Wang, Y. Huang and X. Duan, Adv. Mater., 2013, 25, 5779-5784.

54. J. Zhang, P. Chen, B. H. L. Oh and M. B. Chan-Park, Nanoscale, 2013, 5, 98609866. 
55. Z. Lei, Z. Liu, H. Wang, X. Sun, L. Lu and X. S. Zhao, J. Mater. Chem. A, 2013, 1, 2313-2321.

56. J. Zhu, X. Yang, Z. Fu, J. He, C. Wang, W. Wu and L. Zhang, Chemistry - A European Journal, 2016, 22, 2515-2524.

57. G. Wang, H. Wang, X. Lu, Y. Ling, M. Yu, T. Zhai, Y. Tong and Y. Li, Adv. Mater., 2014, 26, 2676-2682.

58. K. Gao, Z. Shao, J. Li, X. Wang, X. Peng, W. Wang and F. Wang, J. Mater. Chem. A, 2013, 1, 63-67.

59. L. Yuan, B. Yao, B. Hu, K. Huo, W. Chen and J. Zhou, Energy Environ. Sci., 2013, 6, 470-476.

60. Y. J. Kang, S.-J. Chun, S.-S. Lee, B.-Y. Kim, J. H. Kim, H. Chung, S.-Y. Lee and W. Kim, ACS Nano, 2012, 6, 6400-6406.

61. M. Pasta, F. La Mantia, L. Hu, H. D. Deshazer and Y. Cui, Nano Res., 2010, 3, 452-458.

62. L. Hu, J. W. Choi, Y. Yang, S. Jeong, F. La Mantia, L.-F. Cui and Y. Cui, Proceedings of the National Academy of Sciences, 2009, 106, 21490-21494.

63. M. F. El-Kady, V. Strong, S. Dubin and R. B. Kaner, Science, 2012, 335, 13261330.

64. W. Lv, D.-M. Tang, Y.-B. He, C.-H. You, Z.-Q. Shi, X.-C. Chen, C.-M. Chen, P.-X. Hou, C. Liu and Q.-H. Yang, ACS Nano, 2009, 3, 3730-3736.

65. M. J. McAllister, J.-L. Li, D. H. Adamson, H. C. Schniepp, A. A. Abdala, J. Liu, M. Herrera-Alonso, D. L. Milius, R. Car and R. K. Prud'homme, Chemistry of Materials, 2007, 19, 4396-4404.

66. D. Weingarth, H. Noh, A. Foelske-Schmitz, A. Wokaun and R. Kötz, Electrochim. Acta, 2013, 103, 119-124.

67. C. Portet, P. L. Taberna, P. Simon, E. Flahaut and C. Laberty-Robert, Electrochim. Acta, 2005, 50, 4174-4181.

68. M. D. Stoller and R. S. Ruoff, Energy Environ. Sci., 2010, 3, 1294-1301. 